\title{
Role of Water in Formic Acid Decomposition
}

\author{
Naoko Akiya and Phillip E. Savage \\ Dept. of Chemical Engineering, The University of Michigan, Ann Arbor, MI 48109
}

\begin{abstract}
Formic acid decomposes primarily to $\mathrm{CO}$ and $\mathrm{H}_{2} \mathrm{O}$ in the gas phase, but to $\mathrm{CO}_{2}$ and $\mathrm{H}_{2}$ in the aqueous phase. Ab-initio quantum chemical calculations were performed, using Hartree-Fock and density functional methods, to seek an explanation for this behavior. The effect of water on the two decomposition pathways and on the isomerization of formic acid was determined. The transition state structures were fully optimized and include up to two water molecules. In the absence of water, dehydration is more favorable than decarboxylation. The presence of water reduces the activation barriers for both decomposition pathways, but decarboxylation is consistently more favorable than dehydration. The water molecules actively participate in the bond-breaking and bondforming processes in the transition state. The reduction in the activation barriers with the addition of water indicates that water acts as a homogeneous catalyst for both dehydration and decarboxylation, whereas isomerization of formic acid occurs independently of water. Water has a strong effect on the relative stability of the formic acid isomers, acid-water complexes, and transition states. The relative stability of the transition states plays an important role in determining the faster decomposition pathway.
\end{abstract}

\section{Introduction}

Carboxylic acids are important elements in the preparation of various commercial products, resulting in appreciable quantities of carboxylic acids in waste streams (Mishra et al., 1995). In addition, carboxylic acids are frequently observed intermediate products from the oxidation of organic wastes in both gas and aqueous phases (Thornton and Savage, 1990). Hence understanding the decomposition kinetics and mechanisms for these organic acids is important.

Decomposition of formic acid, the simplest carboxylic acid, has been studied both experimentally and theoretically. Although many mechanisms have been suggested in the literature, including free-radical chemistry, ionic chemistry, and surface catalysis, molecular elimination is considered the most important mechanism in both the gas phase (Blake and Hinshelwood, 1960; Hsu et al., 1982; Saito et al., 1984; Goddard et al., 1992; Francisco, 1992) and in the presence of water (Ruelle et al., 1986; Melius et al., 1990). It is generally agreed that the reaction network consists of two parallel pathways:

$$
\begin{aligned}
& \mathrm{HCOOH} \rightarrow \mathrm{CO}_{2}+\mathrm{H}_{2} \text { decarboxylation } \\
& \mathrm{HCOOH} \rightarrow \mathrm{CO}+\mathrm{H}_{2} \mathrm{O} \text { dehydration. }
\end{aligned}
$$

Several experiments on formic acid decomposition have been reported for both the gas phase (Blake and Hinshel-

Correspondence concerning this article should be addressed to P. E. Savage wood, 1960; Blake et al., 1971; Hsu et al., 1982; Saito et al., 1984) and the aqueous phase (Bjerre and Sørensen, 1992; Brill et al., 1996; Yu and Savage, 1998). The gas-phase experiments show that the $\mathrm{CO}$ yield is substantially greater than the $\mathrm{CO}_{2}$ yield, which indicates that dehydration is the primary pathway. On the other hand, the aqueous-phase experiments point to decarboxylation as the main pathway.

This difference in the selectivity in the gas phase and the aqueous phase could possibly be explained by water being a homogeneous catalyst for the decarboxylation pathway (Ruelle et al., 1986). One way to address this issue of water's potential catalytic role is theoretical investigation. Several $a b$ initio quantum chemical calculations for formic acid and its decomposition have been reported (Ruelle et al., 1986; Ruelle, 1987; Melius et al., 1990; Goddard et al., 1992; Francisco, 1992; Kumaresan and Kolandaivel, 1995). Francisco (1992) and Goddard et al. (1992) studied the gas-phase reaction in the absence of water and showed that the activation energy for decarboxylation was slightly higher than that for dehydration, which is consistent with the higher yield of $\mathrm{CO}$ observed in gas-phase experiments.

Ruelle et al. (1986) also studied the gas-phase reaction and suggested that the decarboxylation step in the gas phase is catalyzed by water produced in the dehydration step. They showed that including a single water molecule in the decarboxylation transition-state structure substantially reduced the 
activation barrier for decarboxylation. The quantitative reliability of their calculation has been questioned, however, since some of the transition states they found for formic acid decomposition may be flawed (Francisco, 1992).

Melius et al. (1990) studied the effect of water at high density as a solvating agent and catalyst for the water gas shift reaction $\left(\mathrm{CO}+\mathrm{H}_{2} \mathrm{O}=\mathrm{CO}_{2}+\mathrm{H}_{2}\right)$, which they took to proceed through a formic acid intermediate. They included up to two water molecules in the transition states for dehydration and decarboxylation and demonstrated that both pathways are catalyzed by water. They found that decarboxylation is the favored pathway for all cases considered, even in the absence of water, which is inconsistent with the data obtained from gas-phase experiments (Blake and Hinshelwood, 1960; Blake et al., 1971; Hsu et al., 1982; Saito et al., 1984) and the calculations by Francisco (1992) and Goddard et al. (1992). Since their focus was on the water gas shift reaction rather than the formic acid intermediate, Melius et al. (1990) did not make any distinction between the different isomers of formic acid. Accounting for the relative stability of the cis and trans isomers could affect the activation barriers and hence the selectivity. Furthermore, Melius et al. did not optimize the structure of formic acid stabilized by water molecules to calculate the energy of the hydrated formic acid molecules. Instead, they determined the total energy of the hydrated formic acid as the sum of the energies calculated separately for formic acid and water molecules. Since formic acid and water interact by forming hydrogen bonds, it is unlikely that the total energy of the hydrated formic acid would simply be the sum of the energies of its individual components.

The recent appearance of new experimental data for formic acid decomposition in an aqueous phase (Brill et al., 1996; $\mathrm{Yu}$ and Savage, 1998) and the inability of any of the previous theoretical studies to explain fully all of the available experimental data for formic acid decomposition motivated the present study of the effect of water on formic acid decomposition. We considered three scenarios: formic acid and the decomposition transition states stabilized with (1) zero, (2) one, and (3) two water molecules. Case (1) represents the gas-phase decomposition, and cases (2) and (3) the hydrothermal decomposition. The present work differs from previous theoretical studies in that the formic acid isomers are treated as distinct species, the effect of their relative stability on the activation barriers is considered, and hydrated formic acid isomers are optimized individually to calculate their energies more accurately.

\section{Computational Methods}

Ab-initio calculations were performed with Gaussian 94 revision B.3 (Frisch et al., 1995). The equilibrium geometries of reactants and products were fully optimized with the Berny optimization method (Schlegel, 1982). We used the synchronous transit-guided quasi-Newton method (Peng et al., 1996; Peng and Schlegel, 1993) to locate the transition state structures. Frequency calculations using the analytic second derivatives were performed to compute various thermodynamic quantities as well as the thermal energy corrections to the total electronic energy. We performed the frequency calculations at a temperature $(T)$ and pressures $(p)$ representative of the experimental reaction conditions: $T=700 \mathrm{~K}, p=1$. atm (gas phase)/300 atm (hydrothermal).

Geometry optimizations and frequency calculations were performed with Hartree-Fock theory and the $3-21 \mathrm{G}(\mathrm{d}, \mathrm{p})$ basis set. We performed single-point energy calculations on the optimized geometry, using Becke's three-parameter hybrid method (Miehlich et al., 1989; Becke, 1993) with the Lee, Yang, and Parr correlation functional (Lee et al., 1988) and the $6-311+G(2 d, p)$ basis set. This combination of the theory and basis set was chosen based on the results from a study conducted by Foresman and Frisch (1996), which compared various model chemistries with experimental data. Although all the structures are singlets, bond dissociations occur at transition states, which suggests that the unrestricted method may be required to describe them properly. We conducted several test calculations using both the restricted and unrestricted methods. The results were identical for both methods, even when the HOMO and LUMO were mixed to destroy the spin symmetry for the initial guess of the HartreeFock wavefunction. Therefore, all the results reported in this article are based on calculations using the restricted method. All of the calculations were conducted for molecules in a medium of zero dielectric constant. The dielectric constant of water at $700 \mathrm{~K}$ and $300 \mathrm{~atm}$ is about 3.9 (Haar et al., 1984), however, so we performed several calculations using the self-consistent reaction field methods for reactions in solution and observed no significant change in the numerical results.

\section{Results and Discussion \\ Molecular structures}

Tables 1 and 2 summarize the optimized and experimental ground-state geometries of the trans and cis formic acid iso-

Table 1 Optimized and Experimental Ground-State Geometries for Formic Acid Isomers in the Absence of $\mathrm{Water}_{0}\left(\mathrm{H}_{1} \mathrm{CO}_{1} \mathrm{O}_{2} \mathrm{H}_{2}\right)$ $(\AA$, deg)

\begin{tabular}{|c|c|c|c|c|}
\hline Coordinate & Trans (Calc.) & Trans $($ Exp.)* & Cis (Calc.) & Cis (Exp.) $)^{* *}$ \\
\hline$r\left(\mathrm{O}_{1}=\mathrm{C}\right)$ & 1.198 & $1.202 \pm 0.010$ & 1.192 & $1.1945 \pm 0.0031$ \\
\hline$r\left(\mathrm{C}-\mathrm{H}_{1}\right)$ & 1.074 & $1.097 \pm 0.005$ & 1.081 & $1.1050 \pm 0.0043$ \\
\hline$r\left(\mathrm{C}-\mathrm{O}_{2}\right)$ & 1.354 & $1.343 \pm 0.010$ & 1.358 & $1.3520 \pm 0.0028$ \\
\hline$r\left(\mathrm{O}_{2}-\mathrm{H}_{2}\right)$ & 0.945 & $0.972 \pm 0.005$ & 0.940 & $0.9555 \pm 0.0053$ \\
\hline$\angle\left(\mathrm{O}_{1}=\mathrm{C}-\mathrm{O}_{2}\right)$ & 124.6 & $124.9 \pm 1$ & 122.3 & $122.12 \pm 0.37$ \\
\hline$\angle\left(\mathrm{H}_{1}-\mathrm{C}-\mathrm{O}_{2}\right)$ & 109.4 & $111.0 \pm 2^{\dagger}$ & 113.8 & $114.64 \pm 0.56$ \\
\hline$\angle\left(\mathrm{H}_{1}-\mathrm{C}=\mathrm{O}_{1}\right)$ & 126.0 & $124.1 \pm 2$ & 123.9 & $123.23 \pm 0.58$ \\
\hline$\angle\left(\mathrm{C}-\mathrm{O}_{2}-\mathrm{H}_{2}\right)$ & 111.8 & $106.2 \pm 1$ & 113.3 & $109.68 \pm 0.44$ \\
\hline$\angle\left(\mathrm{H}_{1}-\stackrel{\mathrm{C}}{\mathrm{C}}-\mathrm{O}_{2}-\mathrm{H}_{2}\right)$ & 180.0 & 180.0 & 0.0 & 0.0 \\
\hline
\end{tabular}

* Kwei and Curl (1960)

** Bjarnov and Hocking (1978).

$\uparrow$ Estimated uncertainty. This angle was not given in the original reference. 
Table 2. Optimized and Experimental Ground-State Geometries for Decomposition Products $(\AA, \mathrm{deg})$

\begin{tabular}{llcl}
\hline Species & Coordinate & Calc. & Exp. \\
\hline $\mathrm{CO}$ & $r(\mathrm{C}-\mathrm{O})$ & 1.129 & $1.128^{*}$ \\
$\mathrm{CO}_{2}$ & $r(\mathrm{C}-\mathrm{O})$ & 1.156 & $1.160^{* *}$ \\
$\mathrm{H}_{2}$ & $r(\mathrm{H}-\mathrm{H})$ & 0.737 & $0.739^{\dagger}$ \\
$\mathrm{H}_{2} \mathrm{O}$ & $r(\mathrm{O}-\mathrm{H})$ & 0.941 & $0.958^{*}$ \\
& $\angle(\mathrm{H}-\mathrm{O}-\mathrm{H})$ & 105.8 & $104.5^{*}$ \\
\hline
\end{tabular}

*Francisco (1992).

** Graner et al. (1986)

Jeppesen (1933)

mers and their decomposition products. Experimental uncertainties are given where they are available. Despite the low level of theory and small basis set used for optimization, Tables 1 and 2 show that the predicted and experimental geometries are consistent.

Visualization of the molecular structures provides helpfu] insight into the reaction mechanism. Figures 1 and 2 show the structures of the formic acid isomers and the transition states for the two decomposition pathways in the absence of water. These and all the molecular structures were constructed using the visualization program Xmol, developed by the Minnesota Supercomputer Center (Xmol, 1993). Xmol displays small solid rectangles between atoms that it considers to be close enough to be chemically bonded. We added dashed lines between some atoms to enhance the clarity of the transition-state structures. It is apparent in Figures 1 and 2 that formic acid must be in the appropriate configuration for each decomposition pathway to proceed. In other words, it is the trans isomer of formic acid (Figure 1a), in which the two hydrogen atoms are on opposite sides of the $\mathrm{CO}$ bond, which leads to the dehydration transition-state structure (Figure $1 \mathrm{~b}$ ). In this transition state, formic acid is distorted such that the hydrogen atom bonded to the carbon atom approaches the hydroxyl group, which foreshadows the eventual cleavage of the $\mathrm{CH}$ bond and formation of water and carbon monoxide molecules. Similarly, the cis isomer (Figure 2a), in which the two hydrogen atoms are on the same side of the

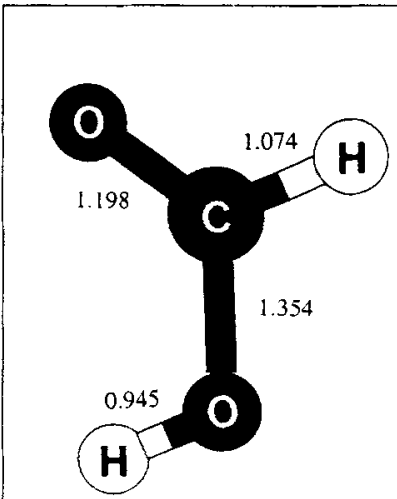

(a)

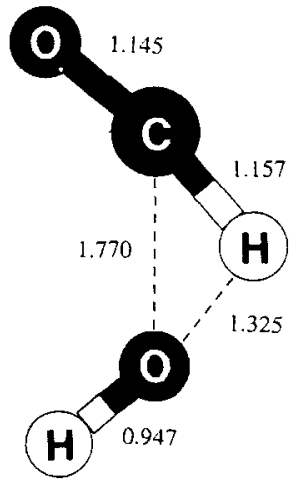

(b)
Figure 1. Predicted structure for: (a) trans formic acid in the absence of water; (b) dehydration transition state connecting trans formic acid with $\mathrm{CO}+\mathrm{H}_{2} \mathrm{O}$.

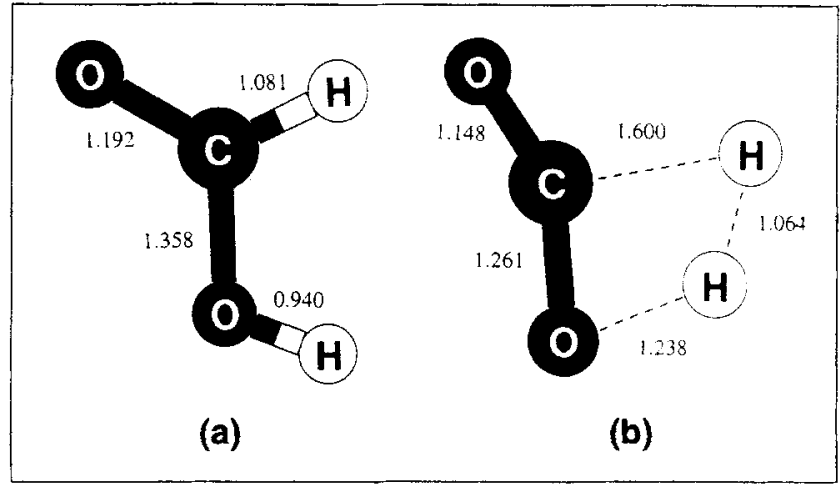

Figure 2. Predicted structure for: (a) cis formic acid in the absence of water; (b) decarboxylation transition state connecting cis formic acid with $\mathrm{CO}_{2}+\mathrm{H}_{2}$.

$\mathrm{CO}$ bond, is the precursor for the decarboxylation transition state structure (Figure 2b). In this case, the two hydrogen atoms approach each other, suggesting the formation of carbon dioxide and hydrogen molecules.

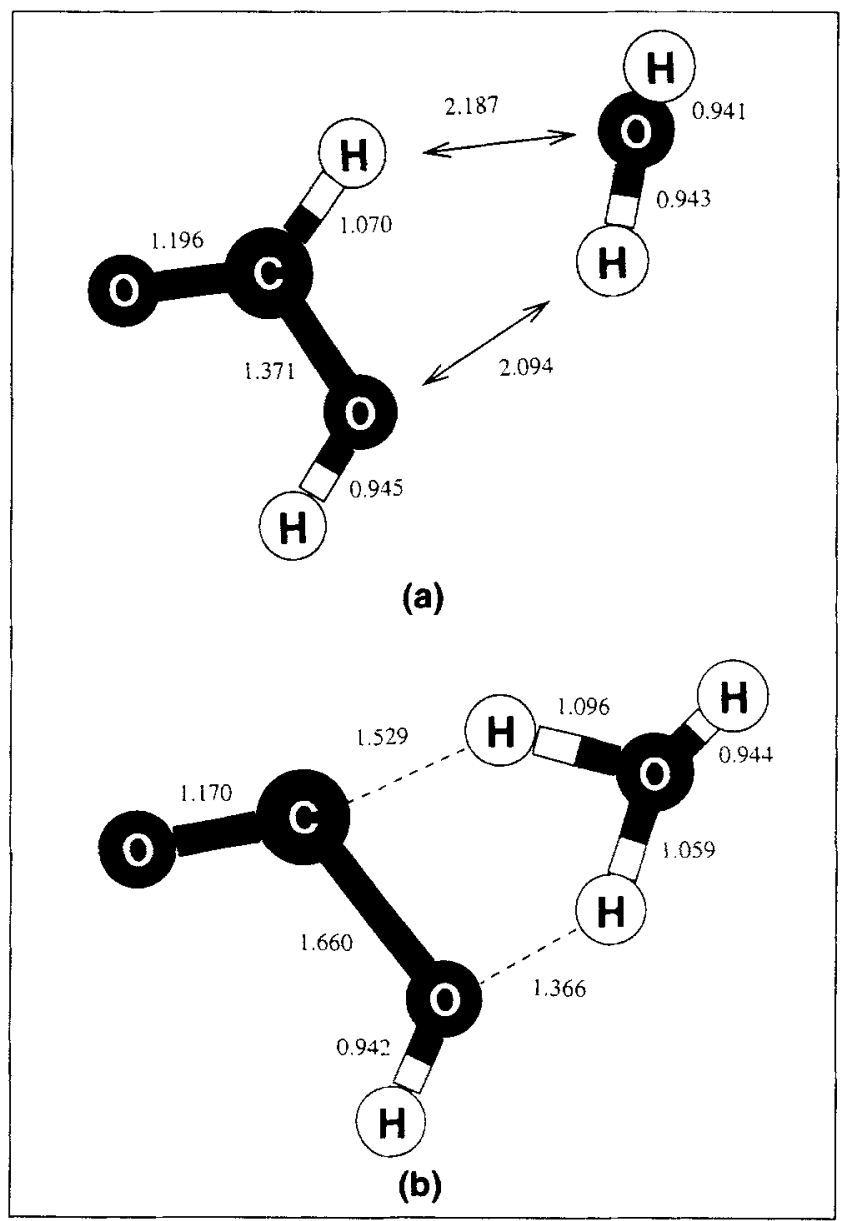

Figure 3. Predicted structure for: (a) trans formic acid with one water molecule (Configuration A); (b) dehydration transition state connecting the trans formic acid plus $\mathrm{H}_{2} \mathrm{O}$ with $\mathrm{CO}+2 \mathrm{H}_{2} \mathrm{O}$. 


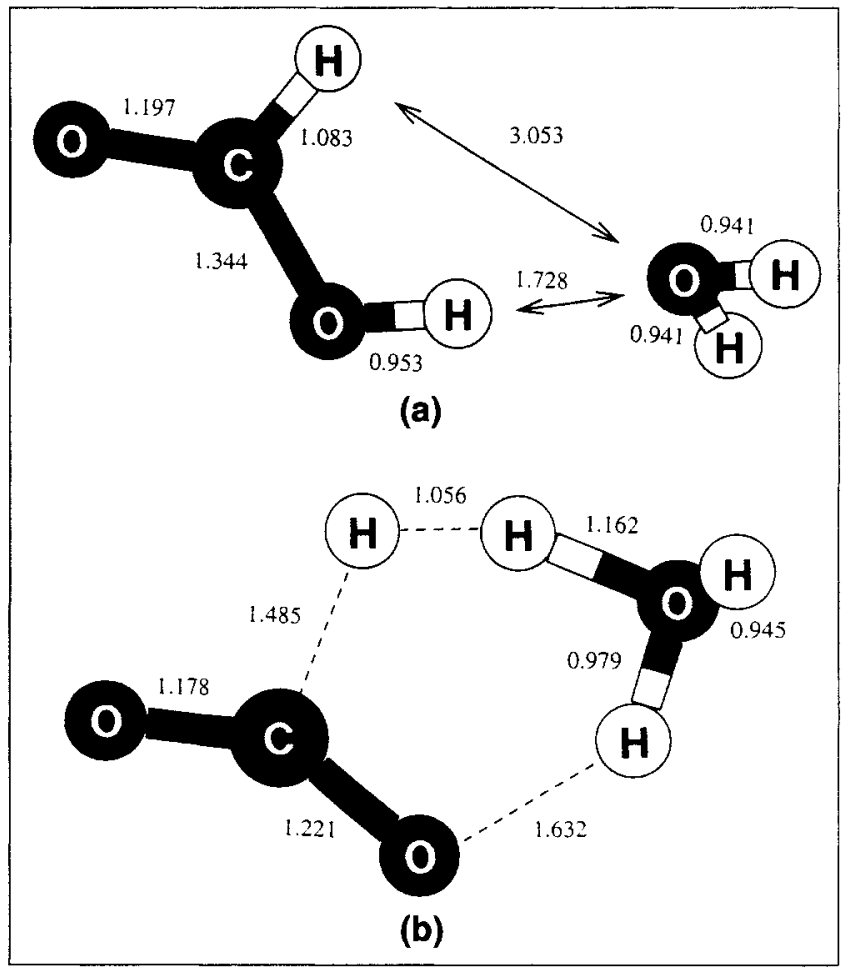

Figure 4. Predicted structure for: (a) cis formic acid with one water molecule (Configuration A); (b) decarboxylation transition state connecting the cis formic acid plus $\mathrm{H}_{2} \mathrm{O}$ with $\mathrm{CO}_{2}+\mathrm{H}_{2}+\mathrm{H}_{2} \mathrm{O}$.

This type of isomer-specific selectivity for different decomposition pathways seen in absence of water is also observed for water-assisted decomposition. Figures 3 and 4 show the optimized formic acid isomers and transition-state structures stabilized with one water molecule, which was initially placed on the side of formic acid opposite the carbonyl oxygen atom. Although the net consumption of water molecules in these reactions is zero, the identity of the atoms in that water molecule is not conserved as a result of water's participation in the bond-breaking and bond-forming processes. In the case of dehydration (Figure 3), one hydrogen atom in the water molecule joins the hydroxyl group in the trans formic acid to form a new water molecule, while the hydrogen bonded to carbon in the acid breaks off to regenerate a water molecule. Similarly, in the case of decarboxylation (Figure 4), one hy. drogen atom from the water molecule joins the hydrogen atom bonded to the carbon atom to form a hydrogen molecule, while the hydrogen atom from the acid hydroxyl group regenerates the water molecule. Figures 5 and 6 show that the decomposition reactions are assisted by two water molecules in a manner similar to that when only one water molecule is present.

\section{Relative energies for the decomposition pathways}

Table 3 presents the total energies of reactants, products, and transition states involved in formic acid decomposition. The total energy is the sum of the electronic energy and the thermal energy correction, which accounts for the energy arising from nuclear motion at a specified temperature and

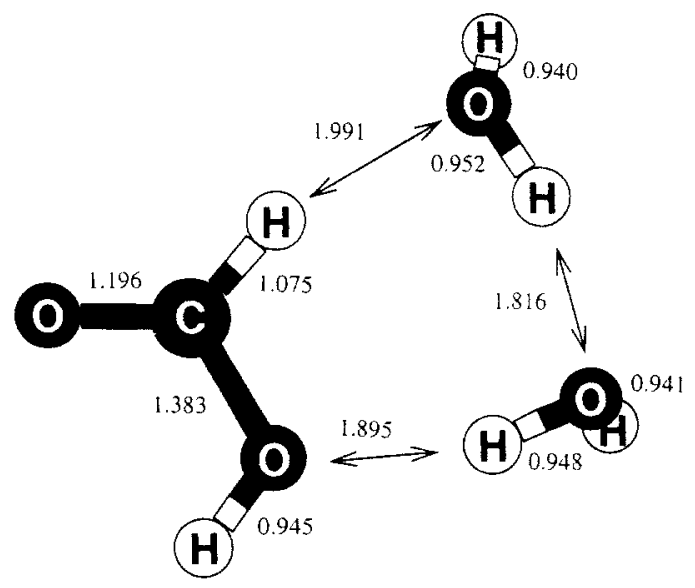

(a)

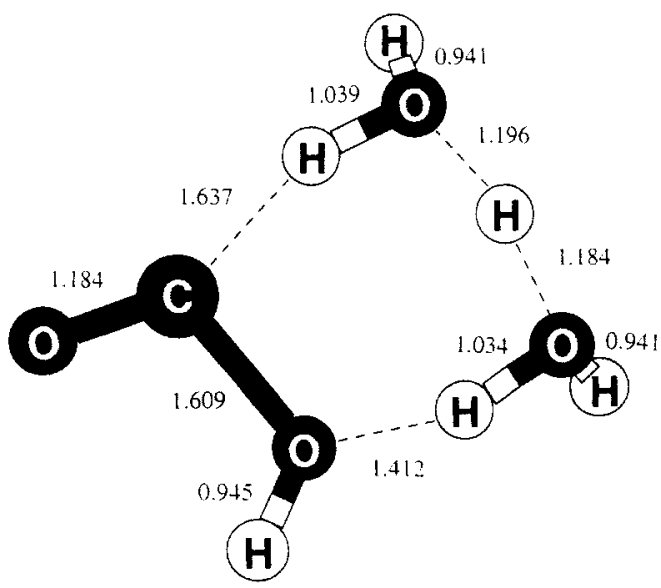

(b)

Figure 5. Predicted structure for: (a) trans formic acid with two water molecules (Configuration A); (b) dehydration transition state connecting the trans formic acid plus $2 \mathrm{H}_{2} \mathrm{O}$ with $\mathrm{CO}+3 \mathrm{H}_{2} \mathrm{O}$.

pressure. Based on this information, the heats of reaction and activation energies were calculated for formic acid decomposition. Since the total energy is temperature dependent, the activation energies are also temperature dependent, that is, they are not Arrhenius activation energies. The relative energies are presented in Figures 7 through 9. Figure 7 is the energy diagram for the gas-phase reactions, constructed with the trans formic acid isomer as the reference point. Figures 8 and 9 are the energy diagrams for the water-assisted pathways, with the cis formic acid isomer as the reference point.

If the activation energies were to be calculated as the difference between the total energies of the transition state and the formic acid isomer that directly transforms to that transition state structure (i.e., the decarboxylation transition state and the cis isomer), decarboxylation would have a lower activation barrier than dehydration in all cases. Such a result, however, would be inconsistent with the experimental observation that dehydration is the favored pathway in the absence of water. This potential inconsistency is circumvented, however, by recognizing that the relative stability of the two formic 


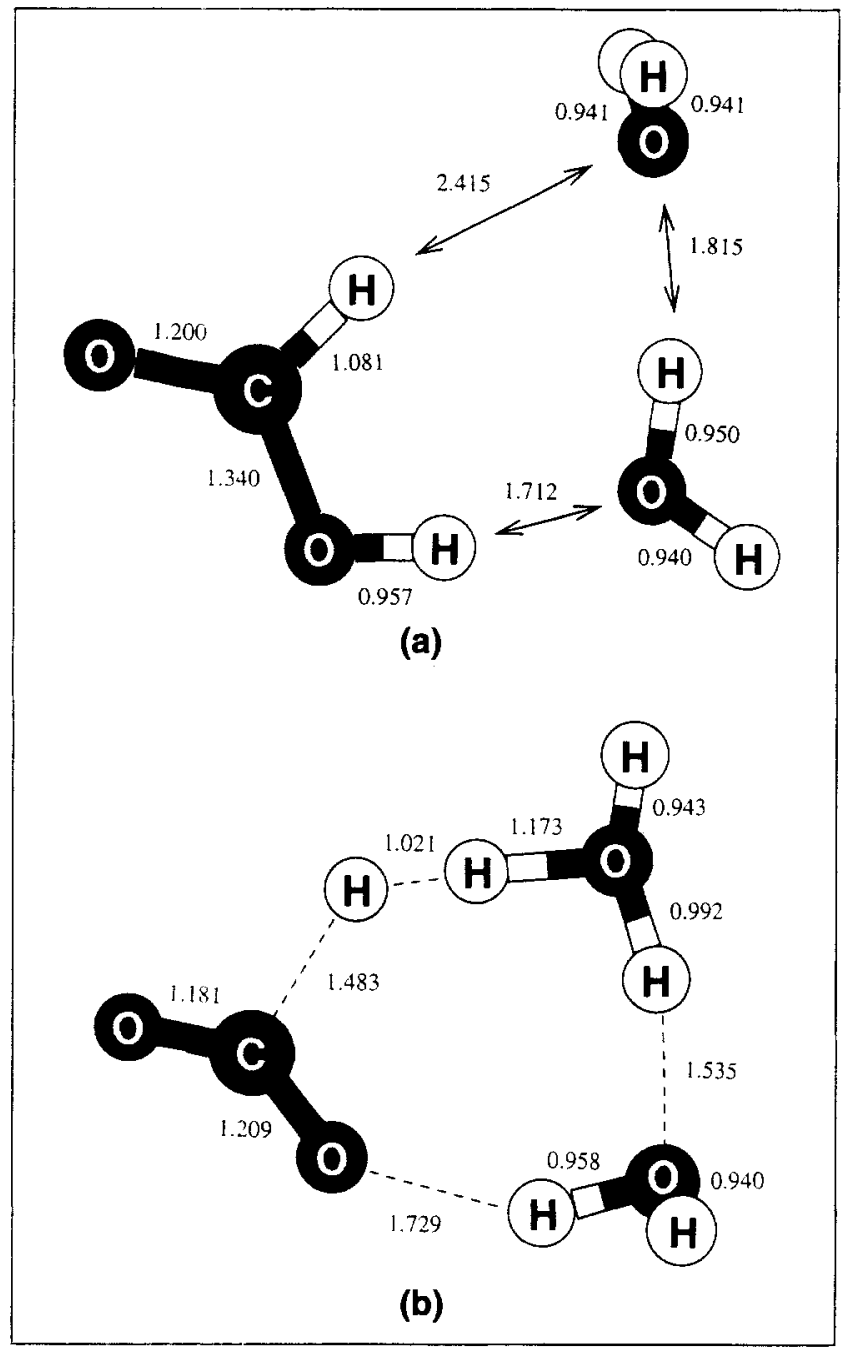

Figure 6. Predicted structure for: (a) cis formic acid with two water molecules (Configuration A); (b) decarboxylation transition state connecting the cis formic acid plus $2 \mathrm{H}_{2} \mathrm{O}$ with $\mathrm{CO}_{2}+\mathrm{H}_{2}$ $+2 \mathrm{H}_{2} \mathrm{O}$.

acid isomers becomes an important factor in determining which decomposition pathway is more favorable. For example, Figure 7 shows that the trans isomer is $4.1 \mathrm{kcal} / \mathrm{mol}$ more stable than the cis isomer in the absence of water. This energy difference is within $0.1 \mathrm{kcal} / \mathrm{mol}$ of previous experimental determinations (Lide, 1966; Hocking, 1976) and electronic structure calculations (Francisco, 1992; Goddard et al., 1992).

Table 3. Total Energies (Hartrees) for Reactants, Products, and Transition-State Structures for Formic Acid Decomposition

\begin{tabular}{lccc}
\hline \multicolumn{1}{c}{ Structure } & $n=0$ & $n=1$ & $n=2$ \\
\hline $\mathrm{CO}+(n+1) \mathrm{H}_{2} \mathrm{O}$ & -189.77140 & -266.20147 & -342.63152 \\
Dehydration TS & -189.67828 & -266.13479 & -342.58408 \\
trans- $\mathrm{HCOOH}-n \mathrm{H}_{2} \mathrm{O}$ & -189.78475 & -266.20980 & -342.64486 \\
cis- $\mathrm{HCOOH}-n \mathrm{H}_{2} \mathrm{O}$ & -189.77822 & -266.21426 & -342.64665 \\
Decarboxylation TS & -189.67674 & -266.14677 & -342.59139 \\
$\mathrm{CO}_{2}+\mathrm{H}_{2}+n \mathrm{H}_{2} \mathrm{O}$ & -189.79522 & -266.22528 & -342.65533 \\
\hline
\end{tabular}

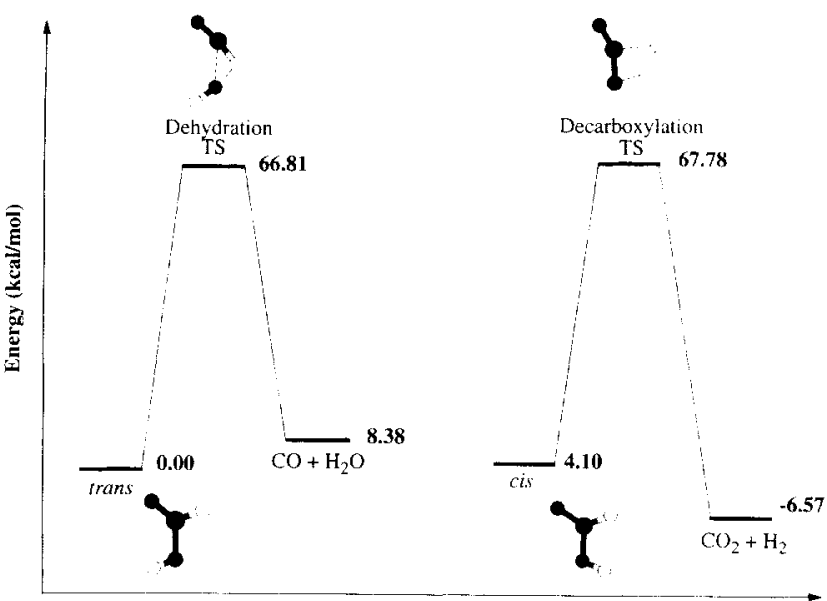

Figure 7. Energy diagram for formic acid decomposition and isomerization in the absence of water.

Since the trans isomer is more stable, most of the formic acid will be in that form. For decarboxylation to take place, trans formic acid must first isomerize to cis formic acid before the appropriate transition-state structure can be formed. Thus, in the absence of water, the effective activation energy for decarboxylation is $67.8 \mathrm{kcal} / \mathrm{mol}(63.68+4.10)$, which exceeds the activation energy for dehydration $(66.8 \mathrm{kcal} / \mathrm{mol})$. This result is consistent with the experimental observation that dehydration is the favored pathway in the absence of water. Note that the result of the ab-initio calculations agree with the selectivity observed experimentally only when one accounts for the relative stability of the formic acid isomers.

The addition of one and two water molecules to formic acid and the transition-state structure lowers the activation barriers for both dehydration and decarboxylation, as shown in Figures 8 and 9. Water acts as a catalyst for both decomposition pathways by altering the transition states, as shown in the b sections of Figures 3-6. Note, however, that the decarboxylation transition state is lower in energy than the de-

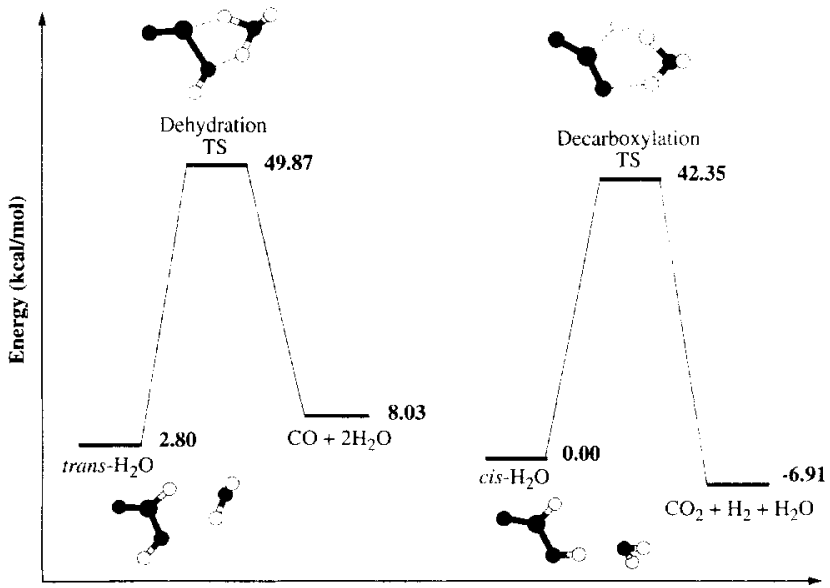

Figure 8. Energy diagram for formic acid decomposition assisted with one water molecule. 


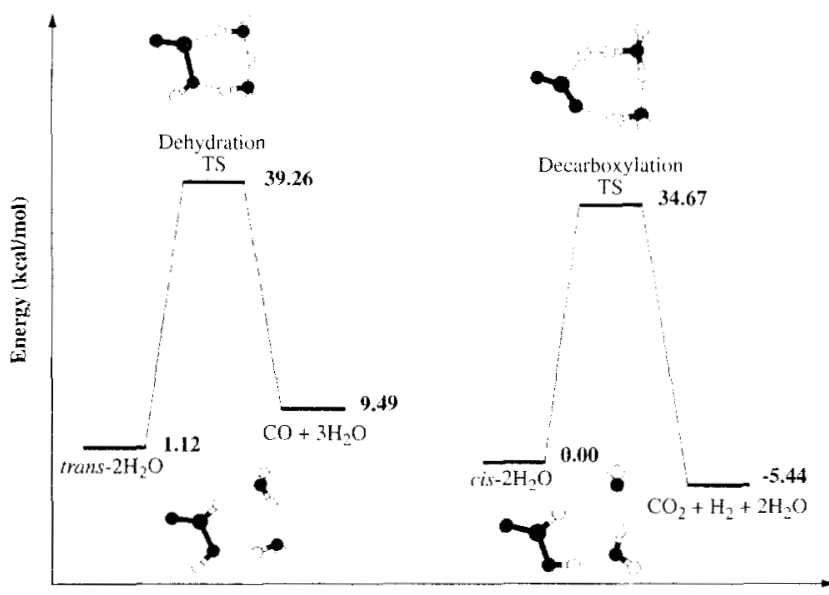

Figure 9. Energy diagram for formic acid decomposition assisted with two water molecules.

hydration transition state for both water-assisted scenarios, which indicates that decarboxylation is the preferred decomposition path in the presence of water. This trend is consistent with the experimental observation that decarboxylation is the main pathway for hydrothermal decomposition of formic acid (Brill et al., 1996; Yu and Savage, 1998).

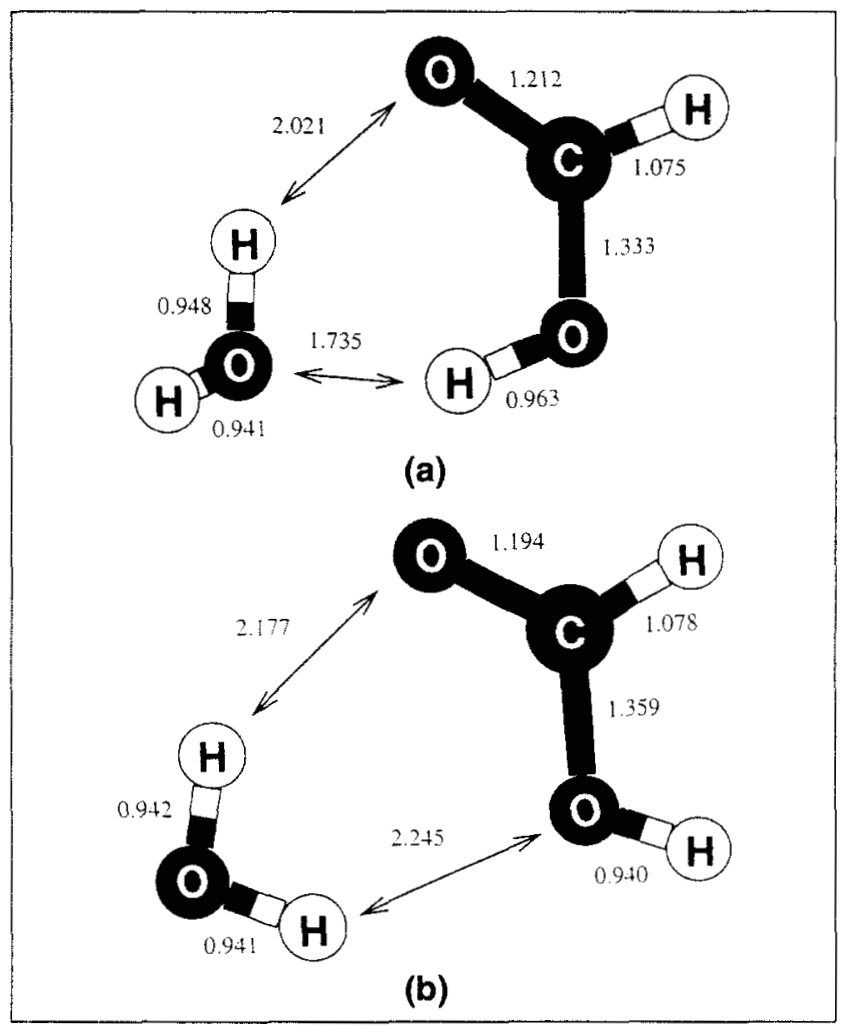

Figure 10. Predicted structure for: (a) trans formic acid with one water molecule (Configuration $B$ ); (b) cis formic acid with one water molecule (Configuration B).
The only configurations of formic acid-water complexes considered thus far are those in the a sections of Figures 3-6, which give rise to the transition states that lead to the dehydration and decarboxylation products. We refer to these reactive configurations as Configuration $\mathrm{A}$ in this section. We recognize, of course, that a formic acid molecule can interact with water molecules in a variety of ways in addition to the configurations considered up to this point. It is possible that some other formic acid-water configuration has a lower energy, in which case the effective activation energies for formic acid decomposition need to be calculated with respect to this lower energy complex. Therefore, alternative formic acid-water complexes that include one and two water molecules were optimized, and they appear in Figures 10 and 11. In these complexes, termed Configuration $\mathrm{B}$, the water molecules are placed facing the $\mathrm{CO}$ bond of formic acid, whereas in Configuration $\mathrm{A}$ the water molecules are positioned away from the $\mathrm{CO}$ bond.

The energies of all the configurations of mono- and dihydrated formic acid isomers considered in this study are shown

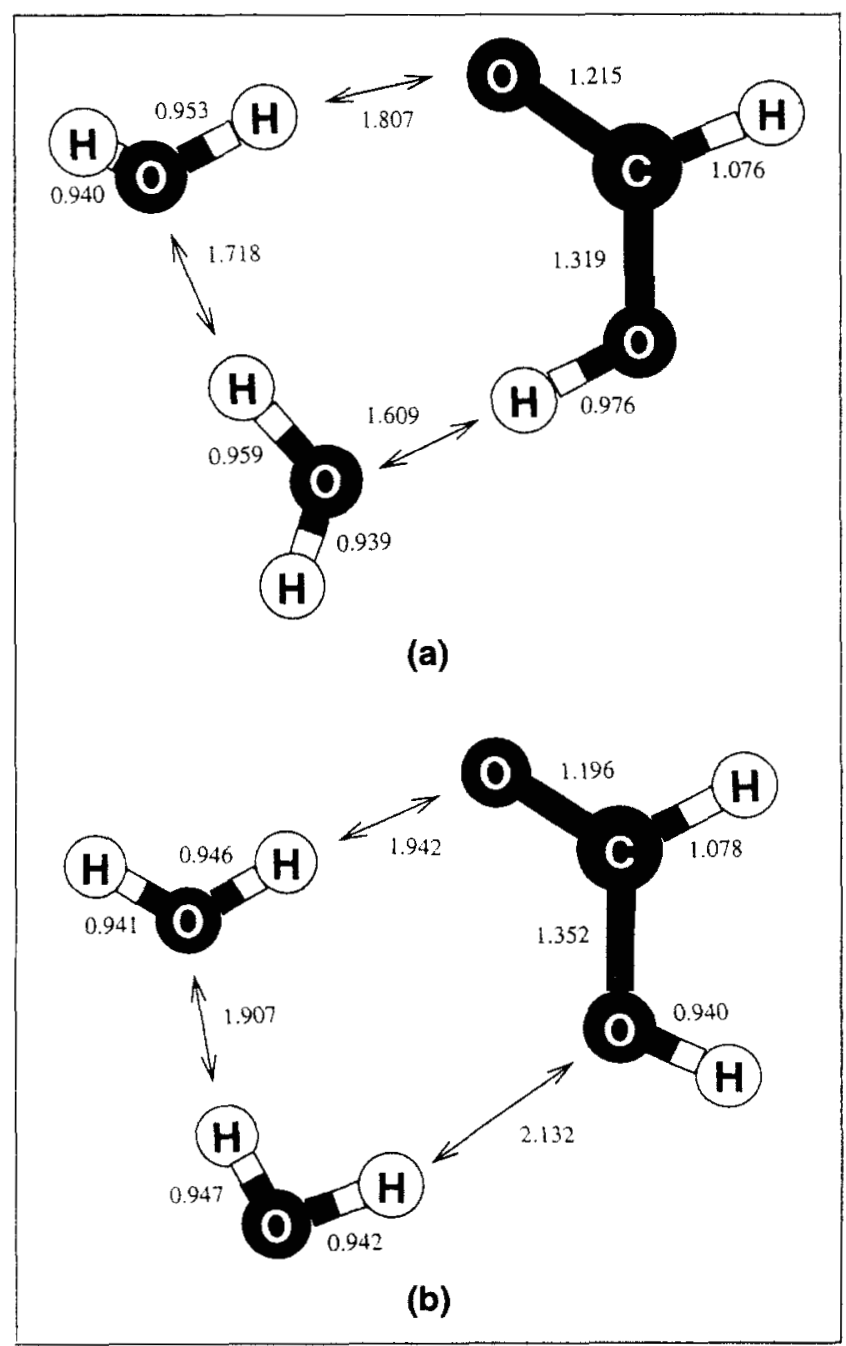

Figure 11. Predicted structure for: (a) trans formic acid with two water molecules (Configuration B); (b) cis formic acid with two water molecules (Configuration B). 


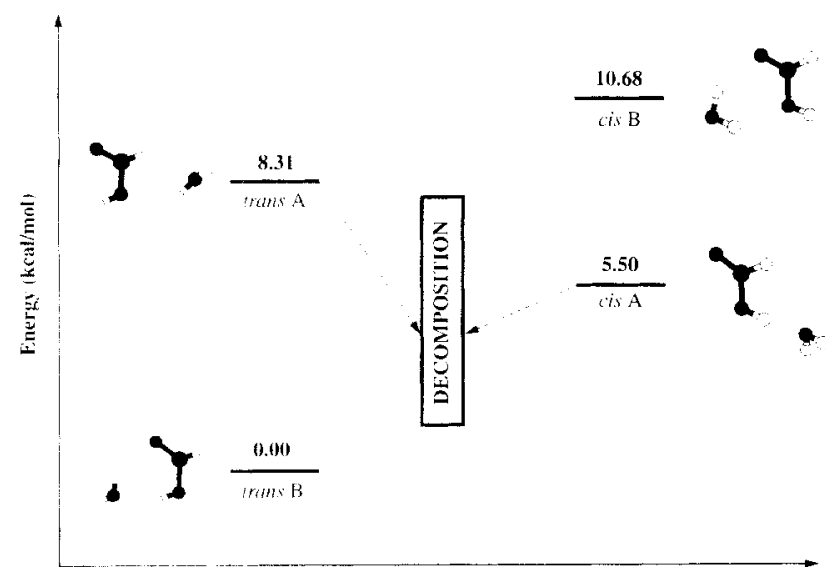

Figure 12. Energy diagram of all the configurations of the monohydrated formic acid isomers considered in this study.

in Figures 12 and 13, respectively. Note that in the presence of both one and two water molecules, the most stable formic acid-water complex is the trans (B) configuration. Since the majority of the formic acid molecules in water will be in the trans (B) configuration, we must account for the energy difference that arises when the trans (B) formic acid-water complex converts to either of the reactive formic acid-water complexes (the trans (A) or cis (A)) when calculating the effective activation energies.

Table 4 summarizes the activation energies for the decomposition pathways calculated relative to the most stable reactant, trans formic acid in the gas phase $(n=0)$ and trans $(\mathrm{B})$ formic acid-water complex for the water-assisted pathways $(n=1,2)$, and compares them with the activation energies

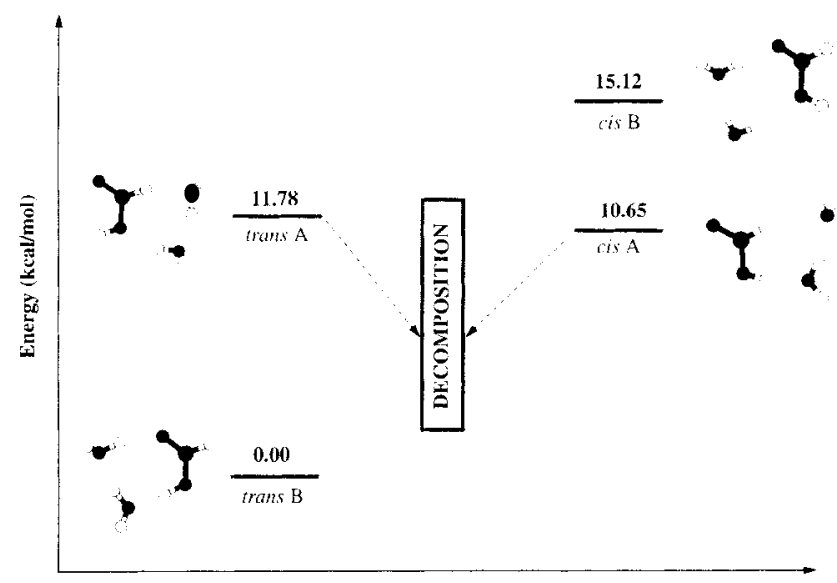

Figure 13. Energy diagram of all the configurations of the dihydrated formic acid isomers considered in this study.

from previous studies. Experimental uncertainty is available only for the activation energy reported by $\mathrm{Yu}$ and Savage (1998). The gas-phase activation energies determined in this study are in good agreement with both experimental data and other theoretical studies. The activation energies for waterassisted decomposition obtained in this study are roughly 10 to $20 \mathrm{kcal} / \mathrm{mol}$ higher than those reported by Melius et al. (1990). This difference is attributed in part to our accounting for the hydrogen bonding that stabilizes the hydrated formic acid complexes and leads to the lower energy formic acid-water configurations. For their energy calculations, Melius et al. used the formic acid and water molecule(s) at infinite separation as the reference state, which corresponds to a dilute gas-phase mixture. Since the transition states cal-

Table 4. Comparison of Activation Energies with Previous Studies (kcal/mol)

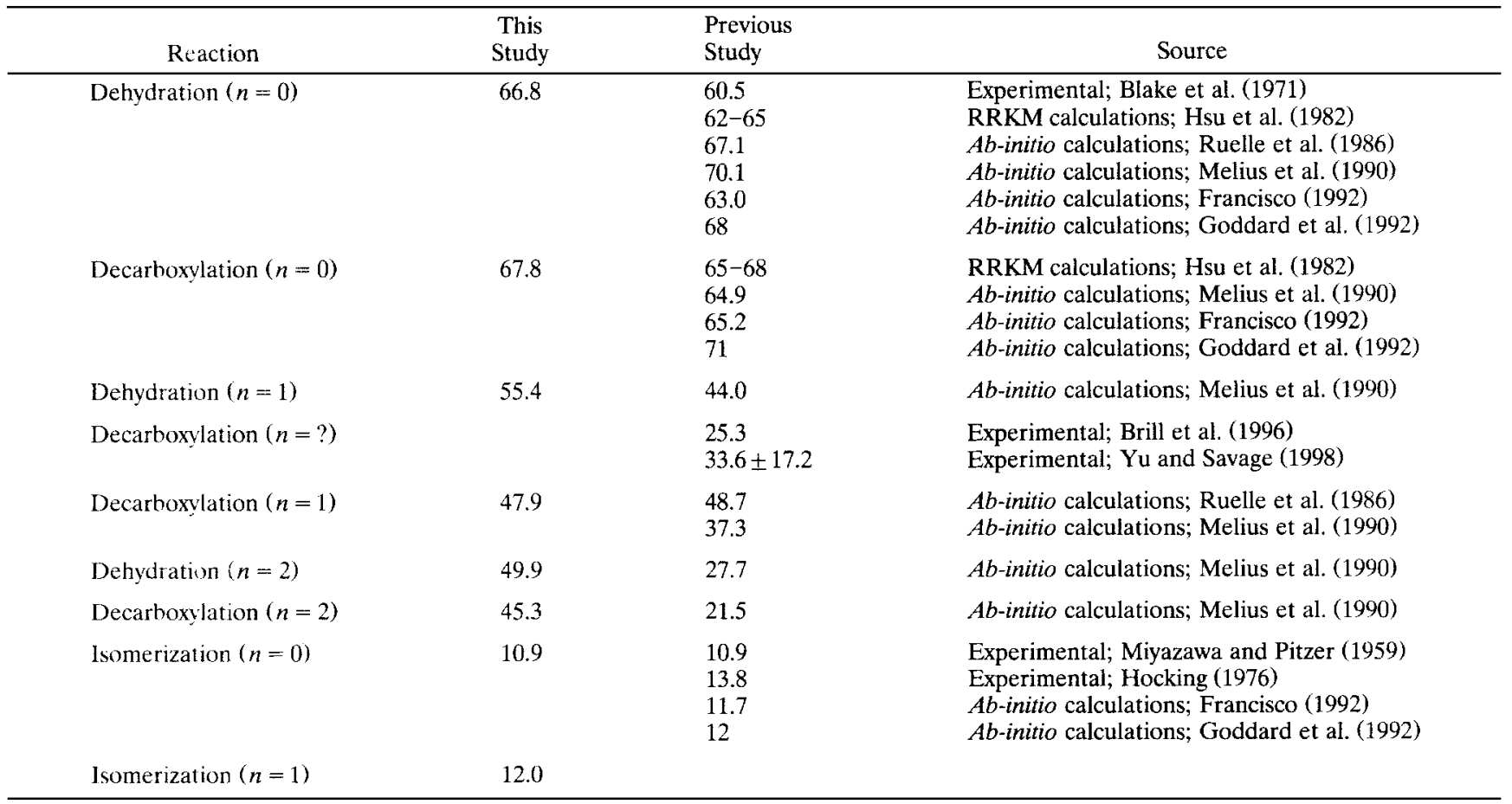


culated in this study and by Melius et al. (1990) appear to be comparable, the activation barriers become greater when we account for the greater stability of the formic acid-water complexes.

\section{Isomerization}

This change in relative stability of the isomers with the position of the water molecule formed the basis for investigating the possibility of isomerization, in the presence of one water molecule, occurring between the most stable forms of the hydrated formic acid isomers, namely cis (A) and trans (B) acid-water dimers. In the absence of water, formic acid isomerization occurs by internal rotation of the hydroxyl group about the $\mathrm{CO}$ bond. Formic acid stabilized by water could possibly isomerize by a different mechanism, since the water molecules surrounding formic acid may hinder the internal rotation. Figure 14 shows the transition state structures for isomerization both in the absence and in the presence of one water molecule. The similarity in the formic acid portion of the two structures suggests that even in the presence of water, isomerization occurs via internal rotation of the hydroxyl group about the $\mathrm{CO}$ bond and that the water molecule merely responds to that rotational movement. Indeed, further analysis showed that as the $\mathrm{OH}$ bond rotates, the oxygen atom of the water molecule diligently follows the hydrogen atom of the hydroxyl group. The activation energies for isomerization from trans to cis formic acid in the absence of water $(10.9 \mathrm{kcal} / \mathrm{mol})$ and in the presence of one water molecule $(12.0 \mathrm{kcal} / \mathrm{mol})$ appear in Table 4 along with those reported in previous studies. The similarity in these activation energies confirms that formic acid isomerization is neither catalyzed nor hindered by the presence of a water molecule. The predicted activation energy relative to the trans isomer in the absence of water is in agreement with both the experimental data and other theoretical studies.

\section{Rate constants}

Rate constants for elementary reactions can be determined from transition-state theory (Laidler, 1987). We will treat all

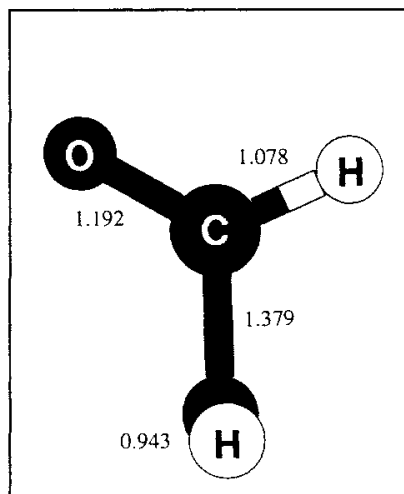

(a)

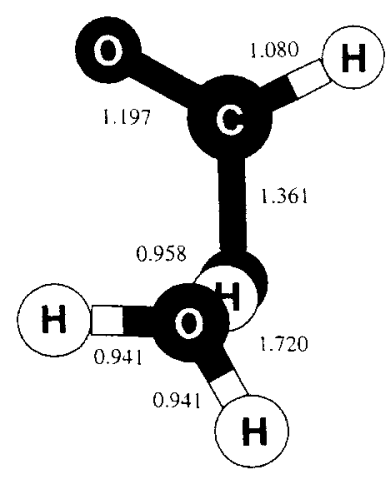

(b)
Figure 14. Predicted structure for: (a) isomerization transition state connecting trans and cis formic acids; (b) isomerization transition state connecting trans formic acid $+\mathrm{H}_{2} \mathrm{O}(\mathrm{B})$ and cis formic acid $+\mathrm{H}_{2} \mathrm{O}(A)$. reactions in this study as being nominally unimolecular. This approach is reasonable because the optimized formic acid-water complexes are lower in energy than the sum of the energies of their individual components and they can be viewed as single molecular entities. For a unimolecular reaction, the transition-state theory rate constant, $k$, is expressed as

$$
k=\left(\frac{k_{B} T}{h}\right)\left(\frac{q_{T S}}{q_{r}}\right) \exp \left(-\frac{E_{0}}{R T}\right),
$$

where $k_{B}$ is Boltzmann's constant, $h$ is Planck's constant, $q_{T S}$ and $q_{r}$ are the partition functions for the transition state and the reactant, respectively, and $E_{0}$ is the threshold energy. The threshold energy is a hypothetical activation energy at absolute zero (Laidler, 1987) and is calculated by taking the difference between the total electronic energies of the reactant and the transition-state species, corrected with the zeropoint vibrational energy. The values of the partition functions are determined as part of the frequency calculation in Gaussian 94, from statistical mechanical expressions for an ideal gas in the canonical ensemble. All the calculations were done at the temperature of $700 \mathrm{~K}$.

Since formic acid decomposition, with or without water, involves proton transfer, quantum mechanical tunneling may have a significant effect on the rate constants. Tunneling corrections were estimated for each reaction using the high-temperature asymptotic form (Shavitt, 1959) of the tunneling correction factor derived for the Eckart barrier (Johnston, 1966). The range of the estimated correction factors was between 1.3 and 2.5. The presence of water reduced the effect of tunneling. In addition, the effect of tunneling was consistently greater for decarboxylation than dehydration, with or without water.

Since transition-state theory applies strictly to elementary reaction steps, each step in the decomposition pathways must be considered explicitly. Therefore, we calculated the rate constants for decarboxylation and dehydration by taking the reactants to be the configurations of formic acid isomers, with or without water, that lead directly to decarboxylation and dehydration transition states, respectively. Note that this configuration is not necessarily the most stable configuration. Table 5 shows the preexponential factors, which include the tunneling corrections. Table 6 shows the threshold energies. The rate constants are calculated from the preexponential factors and the threshold energies, and they are listed in Table 7.

Table 5 shows that in the absence of water $(n=0)$ all the preexponential terms are nearly $10^{13} \mathrm{~s}^{-1}$, as expected for a unimolecular reaction. For the water-assisted decomposition pathways $(n=1,2)$ the preexponential factors are one to two orders of magnitude smaller, which is consistent with the in-

Table 5. $\log _{10}$ of Preexponential Term at $700 \mathrm{~K}\left(\mathrm{~s}^{-1}\right)$

\begin{tabular}{lccc}
\hline \multicolumn{1}{c}{ Reaction } & $n=0$ & $n=1$ & $n=2$ \\
\hline trans- $\mathrm{HCOOH}-n \mathrm{H}_{2} \mathrm{O} \rightarrow \mathrm{CO}+(n+1) \mathrm{H}_{2} \mathrm{O}$ & 13.8 & 12.0 & 11.6 \\
cis $-\mathrm{HCOOH}-n \mathrm{H}_{2} \mathrm{O} \rightarrow \mathrm{CO}_{2}+\mathrm{H}_{2}+n \mathrm{H}_{2} \mathrm{O}$ & 13.6 & 11.4 & 12.1 \\
trans- $\mathrm{HCOOH}-n \mathrm{H}_{2} \mathrm{O} \rightarrow$ cis $-\mathrm{HCOOH}-n \mathrm{H}_{2} \mathrm{O}$ & 13.1 & 14.1 & - \\
cis- $\mathrm{HCOOH}-n \mathrm{H}_{2} \mathrm{O} \rightarrow$ trans $-\mathrm{HCOOH}-n \mathrm{H}_{2} \mathrm{O}$ & 13.0 & 12.9 & - \\
\hline
\end{tabular}


Table 6. Threshold Energies (kcal/mol)

\begin{tabular}{lrrc}
\hline \multicolumn{1}{c}{ Reaction } & $n=0$ & $n=1$ & $n=2$ \\
\hline trans $-\mathrm{HCOOH}-n \mathrm{H}_{2} \mathrm{O} \rightarrow \mathrm{CO}+(n+1) \mathrm{H}_{2} \mathrm{O}$ & 65.9 & 48.5 & 40.0 \\
cis $-\mathrm{HCOOH}-n \mathrm{H}_{2} \mathrm{O} \rightarrow \mathrm{CO}_{2}+\mathrm{H}_{2}+n \mathrm{H}_{2} \mathrm{O}$ & 63.5 & 44.2 & 36.3 \\
trans- $\mathrm{HCOOH}-n \mathrm{H}_{2} \mathrm{O} \rightarrow$ cis $-\mathrm{HCOOH}-n \mathrm{H}_{2} \mathrm{O}$ & 11.5 & 11.9 & - \\
cis $-\mathrm{HCOOH}-n \mathrm{H}_{2} \mathrm{O} \rightarrow$ trans $-\mathrm{HCOOH}-n \mathrm{H}_{2} \mathrm{O}$ & 7.5 & 7.5 & - \\
\hline
\end{tabular}

creasing complexity of the reactions. On the other hand, both the preexponential factors and the threshold energies for isomerization in the presence and absence of water are all about the same, which is consistent with water being largely a spectator during formic acid isomerization.

The rate constants reported in Table 7 agree with the experimentally measured rate constants. The high-temperature rate expression for unimolecular dehydration in the gas phase reported by Blake et al. (1971) gives $3.25 \times 10^{-7} \mathrm{~s}^{-1}$ at $700 \mathrm{~K}$, which is similar to the dehydration rate constant of $2.03 \times$ $10^{-7} \mathrm{~s}^{-1}$ calculated in this study. The first-order rate constants at $700 \mathrm{~K}$ of $0.894 \mathrm{~s}^{-1}$ and $0.630 \mathrm{~s}^{-1}$ can be calculated from experimental results reported by Brill et al. (1996) and Yu and Savage (1998), respectively, for hydrothermal decomposition of formic acid. These experimental first-order rate constants for hydrothermal decomposition fall between the predicted rate constants of $0.00438 \mathrm{~s}^{-1}$ and $5.27 \mathrm{~s}^{-1}$ for decarboxylation assisted with one and two water molecules, respectively.

\section{Product ratios}

Having determined the kinetics of the decomposition and isomerization paths, we can now calculate the ratio of product yields as a ratio of reaction rates. The gas-phase decomposition pathways are given below:

$$
\begin{array}{ccc}
c i s-\mathrm{HCOOH} & \stackrel{\substack{k_{a} \\
\rightarrow}}{\mathrm{CO}_{2}}+\mathrm{H}_{2} \\
k_{b} \uparrow k_{-b} & \\
\text { trans-HCOOH } \stackrel{k_{c}}{\rightarrow} & \mathrm{CO}+\mathrm{H}_{2} \mathrm{O}
\end{array}
$$

The ratio of the yield of $\mathrm{CO}$ relative to the yield of $\mathrm{CO}_{2}$ is given by

$$
\frac{\mathrm{CO}}{\mathrm{CO}_{2}}=\frac{r_{\mathrm{CO}}}{r_{\mathrm{CO}_{2}}}=\frac{k_{c}[\text { trans }]}{k_{a}[\text { cis }]} .
$$

Table 7 shows that the forward and reverse rate constants for isomerization are much larger than those for decomposition. Thus, we can take the isomerization step to be in a quasiequilibrium state and thereby equate the ratio of the concen- trations of cis and trans formic acid with the isomerization equilibrium constant:

$$
\frac{\mathrm{CO}}{\mathrm{CO}_{2}} \cong \frac{k_{c}}{k_{a} K_{b}}
$$

where $K_{b}$ is the equilibrium constant for isomerization, $k_{b} / k_{-\mathrm{b}}$. Substituting the numerical values of the rate constants reported in Table 7 for $n=0$ into Eq. 5 gives $\mathrm{CO}: \mathrm{CO}_{2}$ $\cong 5: 1$. The order of magnitude of this ratio is consistent with the ratio of 10:1 measured experimentally by Blake et al. (1971) for the gas-phase decomposition of formic acid.

The elementary processes involved in formic acid decomposition in the presence of water are outlined below:

$$
\begin{aligned}
& \text { cis-HCOOH (A) } \stackrel{k_{a}}{\rightarrow} \mathrm{CO}_{2}+\mathrm{H}_{2}+\mathrm{H}_{2} \mathrm{O} \\
& K_{b} \uparrow \\
& \text { trans-HCOOH (B) } \\
& K_{c} \uparrow \\
& \text { trans-HCOOH (A) } \stackrel{k_{d}}{\rightarrow} \mathrm{CO}+2 \mathrm{H}_{2} \mathrm{O}
\end{aligned}
$$

The situation is more complex when a water molecule is present because isomerization is now modeled as a two-step process that involves a change in the position of the water molecule relative to trans formic acid, in addition to the isomerization itself. Recognizing that interconversion of the different formic acid-water dimers is rapid relative to decomposition, and using the same approach outlined for the gasphase reactions, we calculate the $\mathrm{CO}_{2} / \mathrm{CO}$ ratio by the following expression:

$$
\frac{\mathrm{CO}_{2}}{\mathrm{CO}}=\frac{k_{a} K_{b}}{K_{c} k_{d}},
$$

where $K_{b}$ is the equilibrium constant for isomerization, and $K_{c}$ is the equilibrium constant for the interconversion of the two trans formic acid-water dimers, A and B. The $n=1 \mathrm{col}$ umn in Table 7 provides the values of $k_{a}, k_{d}$, and $K_{b}$, which is the ratio of the forward and reverse rate constants for isomerization. Rate constants are not available to calculate $K_{c}$, however, since the interconversion of the trans formic acid-water dimers is not a true chemical reaction. Rather, the process involves movement of the water molecule from one side of formic acid to the other side. We determined $K_{c}$ from the difference between the Gibbs free energies of trans

Table 7. Rate Constants at $700 \mathrm{~K}\left(\mathrm{~s}^{-1}\right)$

\begin{tabular}{llll}
\hline Reaction & \multicolumn{1}{c}{$n=0$} & \multicolumn{1}{c}{$n=1$} & $n=2$ \\
\hline trans- $\mathrm{HCOOH}-n \mathrm{H}_{2} \mathrm{O} \rightarrow \mathrm{CO}+(n+1) \mathrm{H}_{2} \mathrm{O}$ & $2.03 \times 10^{-7}$ & $7.57 \times 10^{-4}$ & $1.44 \times 10^{-1}$ \\
cis- $\mathrm{HCOOH}-n \mathrm{H}_{2} \mathrm{O} \rightarrow \mathrm{CO}_{2}+\mathrm{H}_{2}+n \mathrm{H}_{2} \mathrm{O}$ & $5.63 \times 10^{-7}$ & $4.38 \times 10^{-3}$ & $5.27 \times 10^{0}$ \\
trans- $\mathrm{HCOOH}-n \mathrm{H}_{2} \mathrm{O} \rightarrow$ cis $-\mathrm{HCOOH}-n \mathrm{H}_{2} \mathrm{O}$ & $3.10 \times 10^{9}$ & $2.39 \times 10^{10}$ & - \\
cis- $\mathrm{HCOOH}-n \mathrm{H}_{2} \mathrm{O} \rightarrow$ trans $-\mathrm{HCOOH}-n \mathrm{H}_{2} \mathrm{O}$ & $4.35 \times 10^{10}$ & $3.43 \times 10^{10}$ & - \\
\hline
\end{tabular}


(A) and trans (B) formic acid-water dimers, whose values are determined from frequency calculations at $700 \mathrm{~K}$ and $300 \mathrm{~atm}$ :

$$
K=\exp \left(-\frac{\Delta G}{R T}\right)
$$

The change in free energy for interconversion of the trans formic acid-water dimers is $6.48 \mathrm{kcal} / \mathrm{mol}$, so the value of $K_{c}$ is $9.47 \times 10^{-3}$. Based on this equilibrium constant and the rate constants in Table $7, \mathrm{Eq}$. 6 gives $\mathrm{CO}_{2}: \mathrm{CO} \cong 425: 1$. The order of magnitude of this result is consistent with the average $\mathrm{CO}_{2} / \mathrm{CO}$ ratio of $121: 1$ measured experimentally by $\mathrm{Yu}$ and Savage (1998) for hydrothermal decomposition at a temperature of $380^{\circ} \mathrm{C}$ and pressures ranging from 178 to 303 atm.

\section{Conclusions}

The two decomposition pathways, decarboxylation and dehydration, and the isomerization of formic acid in the presence of water were studied by means of $a b$ initio quantum chemical calculations. The predicted activation energies for dehydration and decarboxylation in the absence of water are 66.8 and $67.8 \mathrm{kcal} / \mathrm{mol}$, respectively. These values are in agreement with both the data from gas-phase experiments and the values reported in previous ab-initio studies. The activation energies for dehydration and decarboxylation with one water molecule are 55.4 and $47.9 \mathrm{kcal} / \mathrm{mol}$, respectively, and with two molecules are 49.9 and $45.3 \mathrm{kcal} / \mathrm{mol}$, respectively.

The reduction in the activation energies with the addition of water suggests that water behaves as a homogeneous catalyst for both dehydration and decarboxylation, whereas isomerization occurs independently of water. Although both decomposition pathways are water-assisted, decarboxylation is the favored pathway in the presence of water. The optimized transition-state structures for the decomposition pathways show that water molecules facilitate the bond-breaking and bond-forming processes that lead to product formation. Water also has a strong effect on the relative stability of the transition states, which determines which decomposition pathway is favored energetically.

This study has demonstrated the utility of ab-initio methods in gaining insights into how a solvent may influence the reaction kinetics and mechanisms. There are, however, some limitations inherent to these methods. All the calculations presented in this study involve only up to two solvent molecules. Although such calculations provide some information about the reaction kinetics and valuable insights into the reaction mechanisms on a molecular level, they cannot accurately and completely describe the effect of water as a solvent on the reaction kinetics. In addition, only two types of configurations of hydrated formic acid were considered in this study. There are, however, numerous other possible ways in which a formic acid molecule can interact with surrounding water molecules, some of which could be lower in energy than the configurations considered in this study. For these reasons, the kinetic parameters reported in this study may not correspond exactly to experimentally accessible values.

Further efforts must be made to address the solvent effect completely. To obtain a more detailed picture of the role of water in the reaction, it is necessary to include more than just two water molecules in the formic acid-water cluster. It is computationally infeasible, however, to use ab-initio methods to explicitly consider all possible configurations of hydrated formic acid with multiple water molecules. A more tractable way of approaching this problem is to study the reaction by molecular simulations, either Monte Carlo or molecular dynamics. Molecular simulations allow one to study the averaged effect of a solvent on a reaction. For example, molecular simulations can determine the structure of solvent molecules surrounding the reactive solute, which provides insights into the nature of the solute-solvent interactions and the reaction environment at a molecular level. In addition, molecular simulations can calculate the potential of mean force, from which a reaction profile can be constructed.

\section{Acknowledgments}

This material is based upon work supported under a National Science Foundation Graduate Fellowship. This work was also supported by NSF grant CTS-9521698.

\section{Literature Cited}

Becke, A. D., "Density-Functional Thermochemistry. III. The Role of Exact Exchange," J. Chem. Phys., 98, 5648 (1993).

Bjarnov, E., and W. H. Hocking, "The Structure of the Other Rotamer of Formic Acid, cis-HCOOH," Z. Naturforsch. Teil A, 33, 610 (1978).

Bjerre, A. B., and E. Sorrensen, "Thermal Decomposition of Dilute Aqueous Formic Acid Solutions," Ind. Eng. Chem. Res., 31, 1574 (1992).

Blake, P. G., H. H. Davies, and G. E. Jackson, "Dehydration Mechanisms in the Thermal Decomposition of Gaseous Formic Acid," $J$. Chem. Soc. (B), 1923 (1971).

Blake, P. G, and C. Hinshelwood, "The Homogeneous Decomposition Reactions of Gaseous Formic Acid," Proc. Roy. Soc. (A), 255, 444 (1960).

Brill, T. B., J. W. Schoppelrei, P. G. Maiella, and A. Belsky, "Spectrokinetics of Solvo-Thermal Reactions," Proc. Int. Conf. Solvothermal Reactions, Committee of Solvothermal Technol. Res., Takamatsu, Kagawa, Japan, p. 5 (1996).

Foresman, J. B., and $\boldsymbol{E}$. Frisch, Exploring Chemistry with Electronic Structure Methods, 2nd ed., Gaussian, Inc., Pittsburgh (1996).

Francisco, J. S., "A Comprehensive Theoretical Examination of Primary Dissociation Pathways of Formic Acid," J. Chem. Phys., 96, 1167 (1992).

Frisch, M. J., G. W. Trucks, H.B. Schlegel, P. M. W. Gill, B. G. Johnson, M. A. Robb, J. R. Cheeseman, T. Keith, G. A. Petersson, J. A. Montgomery, K. Raghavachari, M. A. Al-Laham, V. G. Zakrzewski, J. V.Ortiz, J. B. Foresman, C. Y. Peng, P. Y. Ayala, W. Chen, M. W. Wong, J. L. Andres, E. S. Replogle, R. Gomperts, R. L. Martin, D. J. Fox, J. S. Binkley, D. J. Defrees, J. Baker, J. P. Stewart, M. Head-Gordon, C. Gonzalez, and J. A. Pople, Gaussian 94, Rev. B.3, Gaussian, Inc., Pittsburgh (1995).

Goddard, J. D., Y. Yamaguchi, and H. F. Schaefer, "The Decarboxylation and Dehydration Reactions of Monomeric Formic Acid," $J$. Chem. Phys., 96, 1158 (1992).

Graner, G., C. Rossetti, and D. Bailly, "The Carbon Dioxide Molecule: A Test Case for the $\mathrm{r}_{0}, \mathrm{r}_{\mathrm{e}}$, and $\mathrm{r}_{\mathrm{m}}$ Structures," Mol. Phys., 58, 627 (1986).

Haar, L., J. S. Gallagher, and G. S. Kell, NBS/NRC Steam Tables, Hemisphere, Washington, DC (1984).

Hocking, W. H., "The Other Rotamer of Formic Acid, cis-HCOOH," Z. Naturforsch. Teil A, 31, 1113 (1976).

Hsu, D.S., W. M. Shaub, M. Blackburn, and M. C. Lin, "Thermal Decomposition of Formic Acid at High Temperatures in Shock Waves," Proc. Int. Symp. on Combustion, Combust. Inst., Pittsburgh, PA, p. 89 (1982).

Jeppesen, C. R., "The Emission Spectrum of Molecular Hydrogen in the Extreme Ultraviolet," Phys. Rev., 44, 165 (1933). 
Johnston, H. S., Gas Phase Reaction Rate Theory, Ronald Press, New York (1966).

Kumaresan, R., and P. Kolandaivel, "Structure and Stability of the Formic Acid Monomer and the Formic Acid-Water Complex. An ab initio Study," Z. Phys. Chem. 192, 191 (1995).

Kwei, G. H., and R. F. Curl, Jr., "Microwave Spectrum of $\mathrm{O}^{18}$ Formic Acid and Structure of Formic Acid," J. Chem. Phys., 32, 1592 (1960).

Laidler, K. J., Chemical Kinetics, 3rd ed., Harper Collins, New York (1987).

Lee, C., W. Yang, and R. G. Parr, "Development of the Colle-Salvetti Correlation-Energy Formula into a Functional of the Electron Density," Phys. Rev. (B), 37, 785 (1988).

Lide, D. R., Jr., "Microwave Studies of Rotational Isomerism," Trans. Amer. Crystallogr. Assoc., 2, 106 (1966).

Melius, C. F., N. E. Bergan, and J. E. Shepherd, "Effects of Water on Combustion Kinetics at High Pressure," Proc. Int. Symp. on Combustion, Combust. Inst., Pittsburgh, PA, p. 217 (1990).

Miehlich, B., A. Savin, H. Stoll, and H. Preuss, "Results Obtained with the Correlation Energy Density Functionals of Becke and Lee, Yang and Parr," Chem. Phys, Lett., 157, 200 (1989).

Mishra, V. S., V. V. Mahajuni, and J. B. Joshi, "Wet Air Oxidation," Ind. Eng. Chem. Res., 34, 2 (1995).

Miyazawa, T., and K. S. Pitzer, "Internal Rotation and Infrared Spectra of Formic Acid Monomer and Normal Coordinate Treatment of Out-of-Plane Vibrations of Monomer, Dimer, and Polymer," J. Chem. Phys., 30, 1076 (1959).

Peng, C., P. Y. Alaya, H. B. Schlegel, and M. J. Frisch, "Using Re- dundant Internal Coordinates to Optimize Geometries and Transition States," J. Comp. Chem., 17, 49 (1996).

Peng, C., and H. B. Schlegel, "Combining Synchronous Transit and Quasi-Newton Methods for Finding Transition States," Isr. J. Chem., 33, 449 (1993).

Ruelle, P., "Ab Initio Study of the Unimolecular Pyrolysis Mechanisms of Formic Acid: Additional Comments Based on Refined Calculations," J. Amer. Chem. Soc., 109, 1722 (1987).

Ruelle, P., U. W. Kesselring, and H. Nam-Tran, "Ab Initio Quantum-Chemical Study of the Unimolecular Pyrolysis Mechanisms of Formic Acid," J. Amer. Chem. Soc., 108, 371 (1986).

Saito, K., T. Kakumoto, H. Kuroda, S. Torii, and A. Imamura, "Thermal Unimolecular Decomposition of Formic Acid,"J. Chem. Phys., 80, 4989 (1984).

Schlegel, H. B., "Optimization of Equilibrium Geometries and Transition Structures," J. Comp. Chem., 3, 214 (1982).

Shavitt, I., "A Calculation of the Rates of the Ortho-Para Conversions and Isotope Exchanges in Hydrogen," J. Chem. Phys., 31, 1359 (1959).

Thornton, T. D., and P. E. Savage, "Phenol Oxidation in Supercritical Water," J. Supercrit. Fluids, 3, 240 (1990).

XMol, version 1.3.1, Minnesota Supercomputer Center, Inc., Minneapolis, MN (1993).

$\mathrm{Yu}$, J., and P. E. Savage, "Decomposition of Formic Acid under Hydrothermal Conditions," Ind. Eng. Chem. Res., in press (1998).

Manuscript received Aug. 13, 1997, and revision received Nov. 17, 1997. 